\title{
Osteogain ${ }^{\circledR}$ loaded onto an absorbable collagen sponge induces attachment and osteoblast differentiation of ST2 cells in vitro
}

\author{
Richard J. Miron ${ }^{1,2,3}$ • Masako Fujioka-Kobayashi ${ }^{1,4,5}$ • Yufeng Zhang ${ }^{6}$. \\ Anton Sculean $^{7} \cdot$ Benjamin Pippenger $^{8} \cdot$ Yoshinori Shirakata $^{9} \cdot$ Umadevi Kandalam $^{10}$. \\ Maria Hernandez ${ }^{1}$
}

Received: 5 October 2016/Accepted: 23 November 2016

(C) Springer-Verlag Berlin Heidelberg 2016

\begin{abstract}
Objectives Dimensional changes of the alveolar bone following tooth extraction are a major challenge in daily dental practice. To limit bone loss, a variety of biomaterials including bone grafts, barrier membranes, and growth factors have been utilized either alone or in combination therapies to increase the speed and quality of new bone formation. The aim of the present in vitro study was to investigate the regenerative potential of Osteogain ${ }^{\circledR}$, a new liquid carrier system of enamel
\end{abstract}

Richard J. Miron

rmiron@nova.edu

1 Department of Periodontology, College of Dental Medicine, Nova Southeastern University, Fort Lauderdale, FL, USA

2 Cell Therapy Institute, Center for Collaborative Research, Nova Southeastern University, Fort Lauderdale, FL, USA

3 Department of Periodontics and Oral Medicine, University of Michigan School of Dentistry, Ann Arbor, MI, USA

4 Department of Cranio-Maxillofacial Surgery, Bern University Hospital, Inselspital, Bern, Switzerland

5 Department of Oral Surgery, Clinical Dentistry, Institute of Biomedical Sciences, Tokushima University Graduate School, Tokushima, Japan

6 Department of Oral Implantology, University of Wuhan, Wuhan, China

7 Department of Periodontology, University of Bern, Bern, Switzerland

8 Research Department, Institut Straumann AG, Basel, Switzerland

9 Department of Periodontology, Kagoshima University Graduate School of Medical and Dental Sciences, Kagoshima, Japan

10 Department of Pediatric Dentistry, Nova Southeastern University, Fort Lauderdale, USA matrix derivative (EMD) in combination with an absorbable collagen sponge (ACS) specifically designed for extraction socket healing.

Materials and methods The potential of ACS was first investigated using ELISA to quantify total amelogenin adsorption and release from 0 to 10 days. Thereafter, the cellular effects of ST2 pre-osteoblasts were investigated for cellular attachment at $8 \mathrm{~h}$ and cell proliferation at 1,3 , and 5 days as well as osteoblast differentiation by real-time PCR and alizarin red staining for cells seeded on (1) tissue culture plastic, (2) ACS alone, and (3) ACS + Osteogain ${ }^{\circledR}$.

Results ACS efficiently loaded nearly $100 \%$ of the amelogenin proteins found in Osteogain ${ }^{\circledR}$ which were gradually released up to a 10-day period. Osteogain ${ }^{\circledR}$ also significantly induced a 1.5-fold increase in cell attachment and resulted in a 2-6-fold increase in mRNA levels of osteoblast differentiation markers including runt-related transcription factor 2 (Runx2), collagen1a2, alkaline phosphatase, and bone sialoprotein as well as induced alizarin red staining when combined with ACS.

Conclusions In summary, these findings suggest that Osteogain ${ }^{\circledR}$ is capable of inducing osteoblast attachment and differentiation when combined with ACS. Future animal studies and randomized human clinical trials are necessary to further support these findings.

Clinical relevance The use of Osteogain ${ }^{\circledR}$ in combination with ACS may provide a valuable means to limit dimensional changes following tooth extraction.

Keywords Enamel matrix derivative $\cdot$ Enamel matrix proteins $\cdot$ Tooth loss $\cdot$ Tooth extraction $\cdot$ Regenerative therapy $\cdot$ Bone regeneration $\cdot$ Growth factor $\cdot$ Absorbable collagen sponge 


\section{Introduction}

Dimensional changes of the alveolar bone following tooth extraction have been a reported clinical challenge documented in the literature for over 50 years [1]. Over the past decade, much research has been performed since Araújo and Lindhe clearly demonstrated the negative effects of tooth loss on bone remodeling in a canine model following an 8-week healing period [2]. While most studies characterizing dimensional changes are routinely performed in animal models, recent advancements in technology have facilitated the evaluation of ridge alterations in humans by using super-imposed cone-beam CT images [3]. Chappuis et al. recently investigated changes in alveolar bone around maxillary teeth in the esthetic zone where a facial wall thickness less than $1 \mathrm{~mm}$ was reported in $69 \%$ of cases and an average vertical bone loss of $5.2 \mathrm{~mm}$ was reported following an 8 -week healing period [3]. These changes were deemed 2.5 to 3 times more severe than previously found in animal models, thus necessitating alternative strategies to prevent the observed drastic changes in bone volume faced following tooth loss.

Over the past 10 years, a variety of methods have since been utilized to minimize dimensional changes with varying degrees of success including the use of collagen barrier membranes [4-7], bone grafting materials [5, 7-9], and growth factor therapies [10-13]. Despite the numerous attempts that have been investigated to prevent dimensional changes following tooth loss, no single therapy has been able to predictably prevent bone loss following extraction [14-19].

One low-cost method for improving the healing of extraction sockets is by placing a collagen sponge into fresh sockets [10]. Collagen sponges are stable and moldable cone-shaped biomaterials made from natural collagen capable of facilitating blood clot formation through hemostatic wound coverage yet remain fully resorbable over time [10]. Furthermore, they bear the advantage of serving as excellent carriers for growth factors as the natural collagen structure of the biomaterial is ideal for surface coating of growth factors such as bone morphogenetic proteins [10, 17, 20, 21].

One osteopromotive agent recently receiving attention due to its regenerative potential is a liquid carrier system for enamel matrix derivative (EMD) [22-24]. EMD has been utilized primarily as a bioactive agent for the regeneration of periodontal intrabony defects for over 20 years [25]. Despite this, Boyan et al. have demonstrated over a decade ago that EMD contains osteopromotive potential capable of supporting new bone formation when combined with a bone grafting material (demineralized freeze-dried bone allograft (DFDBA)) [26]. Furthermore, EMD has been shown to induce the proliferation of microvascular endothelial cells and speed early angiogenesis in vivo, key events necessary for wound healing of both soft and hard tissues [27-30].

Due to the reported clinical variability following the use of EMD when combined with a bone grafting material, our group recently characterized protein adsorption of EMD to various bone grafting materials including a bovine-derived natural bone mineral (NBM), DFDBA, and a synthetic calcium phosphate with the clinically utilized EMD-gel (Emdogain ${ }^{\circledR}$, Straumann AG, Switzerland) and EMD-liquid (Osteogain $®$, Straumann AG) [22]. The results from that study routinely observed that the liquid formulation of EMD (Osteogain ${ }^{\circledR}$ ) markedly improved protein adsorption of amelogenin to the surface of grafting materials when compared to Emdogain ${ }^{\circledR}[22]$. Furthermore, Osteogain ${ }^{\circledR}$ presented additional advantages including better overall surface coating and penetration of enamel matrix proteins throughout the bone grafting material [22]. It was further shown in an animal model that Osteogain $₫$ in combination with NBM was able to promote new bone formation at early and late time points when compared to bone grafting material utilized alone [24].

Since collagen sponges are low-cost, ideally designed carriers for growth factors, the aim of the present study was to compare the potential of collagen sponges loaded with Osteogain $®$ when compared to collagen sponge alone for the future preservation of extraction sockets following tooth loss. In a first-step study, the kinetics was investigated in vitro on the adsorption and release of amelogenins onto collagen cylindrical sponges designed for extraction sockets, and thereafter, pre-osteoblasts were investigated for their ability to attach, proliferate, and differentiate when Osteogain ${ }^{\circledR}$ was combined with collagen sponges.

\section{Methods}

\section{Osteogain ${ }^{\circledR}$ and absorbable collagen sponges}

For all in vitro experiments, Osteogain ${ }^{\circledR}(0.3-\mathrm{ml}$ vials, starting concentration $30 \mathrm{mg} / \mathrm{ml}$ ) was kindly provided by Straumann AG, Basel, Switzerland. In order to reach the in vitro working concentration of $100 \mu \mathrm{g} / \mathrm{mL}$ for cell biology experiments, Osteogain ${ }^{\circledR}$ was diluted in cell culture media containing $10 \%$ fetal bovine serum (FBS, Gibco, Life technologies, Carlsbad, CA) and $1 \%$ antibiotics including 10,000 units $/ \mathrm{mL}$ of penicillin, $10,000 \mu \mathrm{g} / \mathrm{mL}$ of streptomycin, and $25 \mu \mathrm{g} / \mathrm{mL}$ of amphotericin B (catalog number 15240062, Invitrogen, Carlsbad, CA, USA). An absorbable collagen sponge (ACS: Collacone ${ }^{\circledR}$, Botiss, Berlin, Germany) was utilized as the material of choice due to its utilization in extraction sockets as a low-cost material with the ability to efficiently adsorb growth factors due to its three-dimensional collagen scaffold [10]. For in vitro experiments with cells, cylindrical scaffolds were cut into cylindrical disks about $1 \mathrm{~mm}$ in thickness and inserted into the bottom of 24-well dishes (Invitrogen). Samples were coated with Osteogain ${ }^{\circledR}$ for $5 \mathrm{~min}$ prior to protein quantification experiments as well as cell seeding experiments. 


\section{ELISA protein quantification of Osteogain $₫$ adsorption to collagen sponges}

To determine the quantity of Osteogain ${ }^{\circledR}$ adsorption to the surface of ACSs, ELISA quantification assay was utilized for amelogenins, the main protein found in EMD representing $90-95 \%$ of the total protein content. Briefly, after the coating period incubation of $0.3 \mathrm{~mL}$ of Osteogain ${ }^{\circledR}$ onto one full-sized ACS at $4{ }^{\circ} \mathrm{C}$, the remaining PBS solution, containing unattached enamel matrix proteins, was collected and quantified by a Quantikine Colorimetric Sandwich ELISA (Gene 301200, MyBioSource Inc., San Diego, CA, USA) for the remaining amount of amelogenin protein unadsorbed to ACS according to the manufacturer's protocol. Substraction of total coated protein from the amount of un-adsorbed protein was used to determine the amount of adsorbed material to the surface of ACS as previously described [22]. Furthermore, in order to determine the quantity of amelogenin protein being released from ACS over time, coated collagen sponges were soaked in $1 \mathrm{~mL}$ of PBS and samples were collected at various time points including $15 \mathrm{~min}, 1 \mathrm{~h}, 8 \mathrm{~h}, 1$ day, 3 days, and 10 days. All samples were quantified in triplicate, and three independent experiments were performed.

\section{Cell culture system}

Undifferentiated mouse cell line ST2 stromal bone marrow cells were obtained from RIKEN Cell Bank (Tsukuba, Japan). No ethical approval was required for this study because of the cell source utilized. Cells were detached from the tissue culture plastic using $0.25 \%$ EDTA-Trypsin prior to reaching confluency (Invitrogen). During cell seeding for differentiation experiments, Dulbecco's modified Eagle medium (DMEM) (Gibco) was supplemented with $10 \% \mathrm{FBS}, 50 \mu \mathrm{g} / \mathrm{mL}$ ascorbic acid (Sigma, St. Louis, MO, USA), and $10 \mathrm{mM} \beta$ glycerophosphate (Sigma) to promote osteoblast differentiation as previously described [31]. ST2 cells were seeded on either (1) tissue culture plastic (TCP) alone, (2) ACS alone, and (3) ACS $+100 \mu \mathrm{g} / \mathrm{mL}$ of Osteogain ${ }^{\circledR}$ at a density of 10,000 cells in 24-well culture plates for cell adhesion and proliferation experiments and 50,000 cells per well in 24-well dishes for real-time PCR and alizarin red experiments. For experiments lasting longer than 5 days, the medium was replaced twice weekly containing osteoblast differentiation media accordingly.

\section{Adhesion and proliferation assay}

Cells were quantified using an MTS assay (Promega, Madison, WI, USA) at $8 \mathrm{~h}$ for cell adhesion and at 1,3 , and 5 days for cell proliferation according to the manufacturer's protocol. At desired time points, cells were washed with PBS and quantified using an ELx808 Absorbance Reader (BioTek, Winooski, VT, USA). Experiments were performed in triplicate with three independent experiments for each condition. Data were analyzed for statistical significance using Student $t$ test for adhesion assay and two-way analysis of variance with Turkey test for proliferation assay $(* p$ values $<0.05$ were considered significant).

\section{Real-time PCR for osteoblast differentiation markers}

Real-time RT-PCR was used to investigate the expression of genes encoding osteoblast differentiation markers. Total RNA was isolated using High Pure RNA Isolation Kit (Roche, Basel, Switzerland) at 3 and 14 days. Primer and probe sequences for genes encoding runt-related transcription factor 2 (Runx2), collagen $1 \alpha 2$ (COL1A2), alkaline phosphatase (ALP), bone sialoprotein (BSP), and glyceraldehyde 3phosphate dehydrogenase (GAPDH) were fabricated with primer sequences according to Table 1. Reverse transcription was performed with Transcriptor Universal cDNA Master. Real-time RT-PCR was performed using Roche FastStart Universal SYBR Green Master and quantified on an Applied Biosystems 7500 Real-Time PCR Machine (Biosystems, Life Technologies Corporation, Carlsbad, CA). A NanoDrop 2000c (Thermo, Wilmington, DE, USA) was used to quantify total RNA levels. All samples were assayed in triplicate with three independent experiments performed. The $\Delta \Delta \mathrm{Ct}$ method was used to calculate gene expression levels normalized to total RNA values and calibrated to control samples [32]. Data were analyzed for statistical significance using two-way analysis of variance with Tukey test $\left({ }^{*} p\right.$ values $<0.05$ were considered significant).

\section{Alizarin red staining}

Alizarin red staining was performed to determine the presence of extracellular matrix mineralization. After 14 days, cells were fixed in $96 \%$ ethanol for $15 \mathrm{~min}$ and stained with $0.2 \%$ alizarin red (Alizarin Red S, Sigma) solution in water (pH 6.4) at room temperature for $1 \mathrm{~h}$. Alizarin red quantification was
Table 1 PCR primers for genes encoding

Runx2, ALP, COL1a2, $\mathrm{BSP}$, and GAPDH

\begin{tabular}{ll}
\hline Gene & Primer sequence \\
\hline mRUNX2 F & agggactatggcgtcaaaca \\
mRUNX2 R & ggctcacgtcgctcatctt \\
mCOLa2 F & gagctggtgtaatgggtcct \\
mCOLa2 R & gagacccaggaagacctctg \\
mALP F & ggacaggacacacacacaca \\
mALP R & caaacaggagagccacttca \\
mBSP F & gcactccaactgcccaaga \\
mBSP R & tttggagccctgctttctg \\
mGAPDH F & aggtcggtgtgaacggatttg \\
mGAPDH R & tgtagaccatgtagttgaggtca \\
\hline
\end{tabular}


performed using images captured on a Nikon D610 camera with a Heerbrugg M400 Zoom microscope (Wild Heerbrugg, Switzerland). ImageJ software was used to quantify data using set parameters for color intensity staining of red using a color threshold including parameters for hue (0 to 255), saturation (50 to 255 ), and brightness (100 to 255 ). The same threshold values were used for all analyzed samples. Alizarin red experiments were performed in triplicate with three independent experiments. Means and standard errors (SE) were calculated, and the statistical significance of differences was examined by one-way analysis with Turkey test between all groups $(* p$ values $<0.05$ were considered significant).

\section{Statistical analysis}

Statistical analyses were performed using one- or two-way ANOVA and the Student-Newman-Keuls test, and statistical significance was considered at $p<0.05$. All the in vitro experiments were performed in triplicate and from three independent experiments unless otherwise mentioned. All statistical analysis and display of figures were performed using GraphPad Prism software version 7.0 (La Jolla, CA, USA).

\section{Results}

\section{Ability of ACS to adsorb and release amelogenin over time}

Analysis of the total amount of adsorbed amelogenin to ACS after a 5-min pre-coating period with Osteogain ${ }^{\circledR}$ revealed a near $100 \%$ adsorption of amelogenin proteins (Fig. 1). Furthermore, after rinsing with PBS, the total remaining content contained within the ACS was reported close to $100 \%$ with only an average $2 \%$ decrease in total amelogenin loss (Fig. 1). The amount of amelogenin was slowly and gradually released over time from 15 min up to 10 days (Fig. 1). After a 10-day period, nearly $70 \%$ of the initial protein content found in EMD remained present on the surface and within the ACS structure, thus demonstrating good protein adsorption properties of collagen sponges (Fig. 1).
(A)
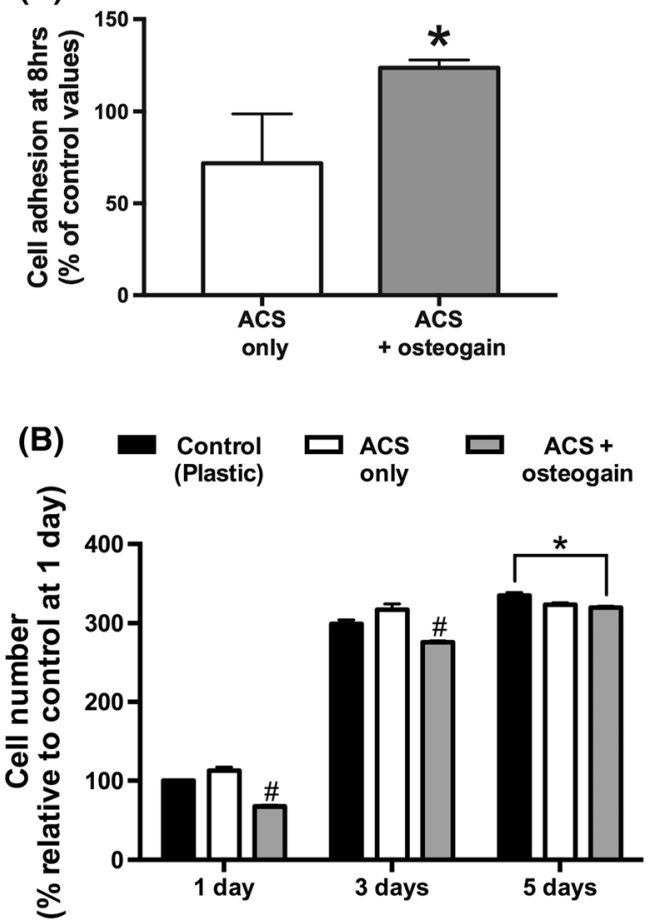

Fig. 2 a Attachment ( $8 \mathrm{~h}$ ) and $\mathbf{b}$ proliferation (1, 3, and 5 days) assays of ST2 cells seeded on (1) control tissue culture plastic, (2) control absorbable collagen sponges (ACS), and (3) ACS + Osteogain ${ }^{\circ}$. (Number symbol denotes significantly lower than all other groups, $p<0.05$; asterisk denotes significant difference, $p<0.05$ )

\section{Effect of ACS and Osteogain ${ }^{\circledR}$ on ST2 cell adhesion and proliferation}

Thereafter, the effects of ACS in combination with Osteogain ${ }^{\circledR}$ were investigated on ST2 cell adhesion at $8 \mathrm{~h}$ and cell proliferation at 1,3 , and 5 days post seeding (Fig. 2). It was first observed that while ACS did not induce ST2 cell attachment relative to tissue culture plastic, the additional use of Osteogain ${ }^{\circledR}$ significantly increased cell adhesion at $8 \mathrm{~h}$ by $50 \%(p<0.05$, Fig. 2a). Thereafter, the effects of ACS in combination with Osteogain $\AA$ were tested for their ability to induce cell proliferation (Fig. 2b). While no significant differences were observed between tissue culture plastic and ACS,
Fig. 1 Amelogenin adsorption of Osteogain ${ }^{\circledR}$ to absorbable collagen sponges (ACSs) at $0 \mathrm{~min}, 15 \mathrm{~min}, 60 \mathrm{~min}, 8 \mathrm{~h}, 24 \mathrm{~h}$,

3 days, and 10 days as quantified by ELISA. ACS was able to efficiently adsorb amelogenins and demonstrated a slow and gradual release over a 10-day period

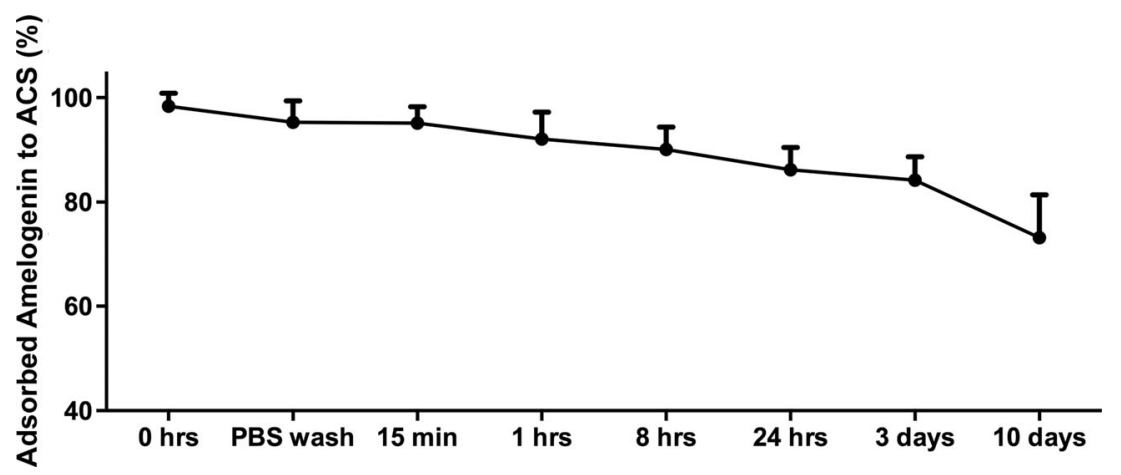


the additional coating with Osteogain ${ }^{\circledR}$ significantly decreased cell numbers at 1,3 , and 5 days ( $p<0.05$, Fig. 2 b).

\section{Effect of ACS and Osteogain ${ }^{\circledR}$ on $\mathrm{ST} 2$ cell differentiation to osteoblasts}

We then investigated the effects of ACS and Osteogain ${ }^{\circledR}$ on ST2 differentiation towards osteoblasts utilizing real-time PCR (Fig. 3) as well as alizarin red staining (Fig. 4). It was first observed that neither ACS nor Osteogain ${ }^{\circledR}$ had any influence on genes encoding Runx2, Col1a2, ALP, and BSP at an early time point of 3 days post seeding (Fig. 3). However, at 14 days post seeding, it was found that ACS significantly increased Runx2 messenger RNA (mRNA) levels up to 2fold, and Osteogain ${ }^{\circledR}$ further significantly upregulated all osteoblast differentiation markers including Runx2, Col1a2, ALP, and BSP between 2- and 6-fold when compared to standard tissue culture plastic alone (Fig. 3). Furthermore, the ability for cells to produce mineralized tissue was investigated via alizarin red staining (Fig. 4). It was found that cells seeded with ACS + Osteogain ${ }^{\circledR}$ significantly enhanced alizarin red staining when compared to all other groups (Fig. 4).

\section{Discussion}

The aim of the present in vitro study was to investigate the potential of Osteogain $®$ in combination with ACS as a potential future regenerative strategy for extraction socket management. While the effects of tooth loss have been reported in the literature in numerous studies and review articles [2, 3, 14-19], the investigation of innovative strategies to prevent dimensional changes following tooth extraction remains necessary. Therefore, the combination of several bioactive factors with bone biomaterials needs to be more accurately tested in cell cultures before performing larger and more expensive animal and human studies.

While it has been reported in the literature by numerous investigators that absorbable collagen sponges serve as the preferred carrier system for bone morphogenetic proteins (BMPs) [10, 17, 20, 21], we investigated for the first time their ability to load a novel carrier system for enamel matrix proteins in a liquid carrier system (Osteogain $®)$. Noteworthy, amelogenin was chosen as the quantified protein in the ELISA investigation as it represents over $90 \%$ of the total protein found in the Osteogain $®$ formulation. No other possibility existed for quantification purposes as no ELISA exists
Fig. 3 Real-time PCR of ST2 cells seeded on (1) control tissue culture plastic, (2) control absorbable collagen sponges (ACS), and (3) ACS + Osteogain $®$ for genes encoding a Runx2, b Collagen 1 alpha 2 (COL1a2), $\mathbf{c}$ alkaline phosphatase (ALP), and $\mathbf{d}$ bone sialoprotein (BSP) at 3 and 14 days post seeding (Number symbol denotes significantly lower than all other groups, $p<0.05$; double asterisks denote significantly higher than all other treatment modalities, $p<0.05$ )
(A)

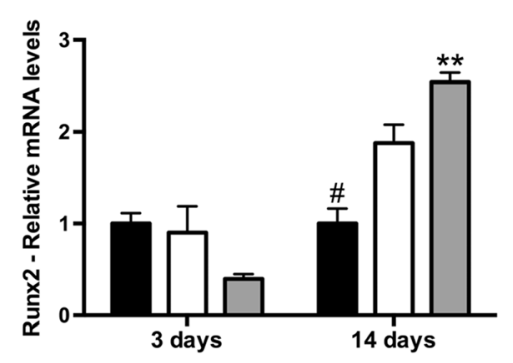

(C)

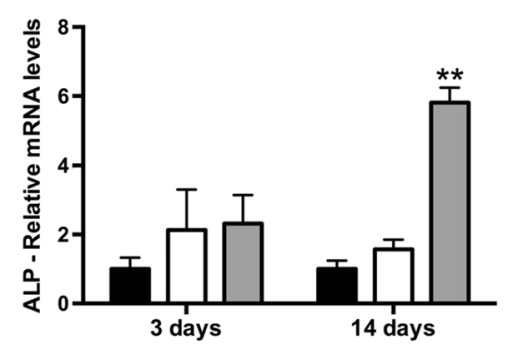

(E)

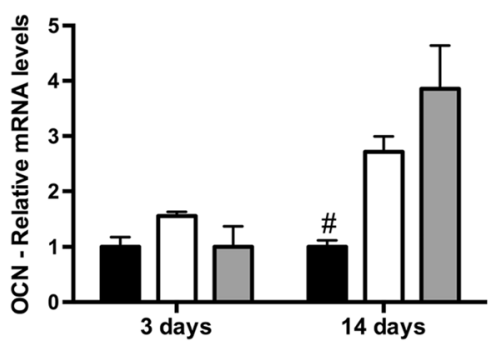

(B)

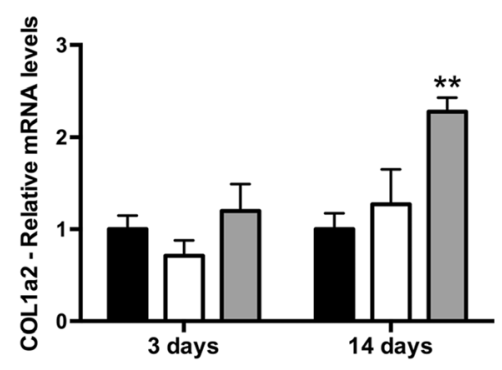

(D)

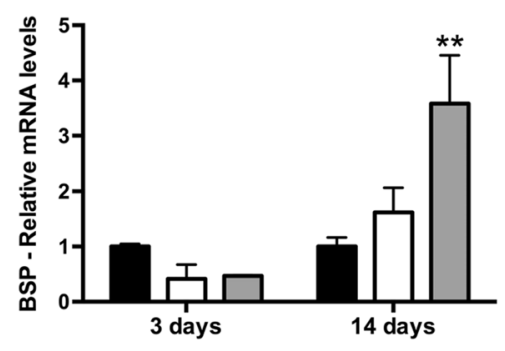


(A)

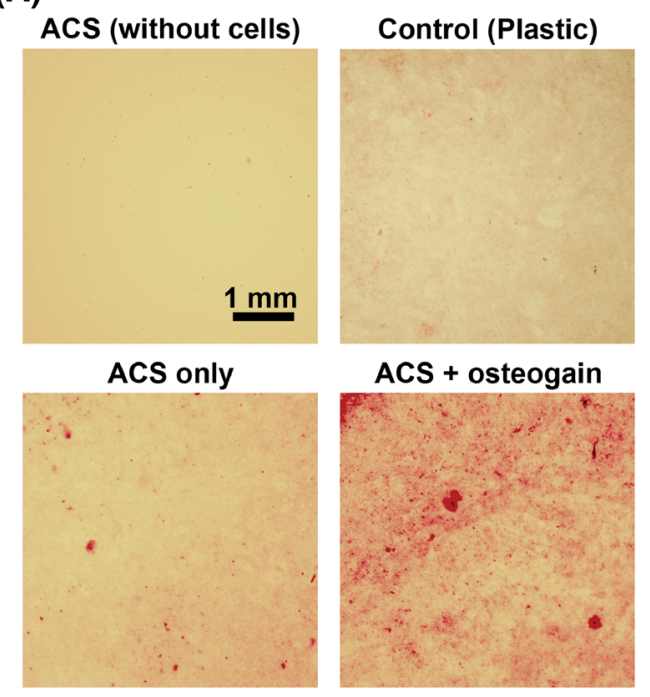

(B)

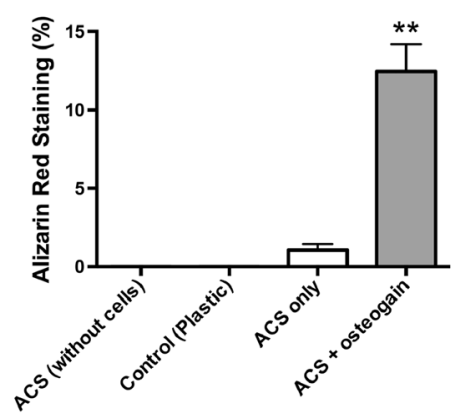

Fig. 4 a Visual representation of alizarin red stained on (1) negative control absorbable collagen sponges (ACS) without cells, (2) control tissue culture plastic, (3) control ACS with cells, and (4) ACS with Osteogain $®$ at 14 days post seeding. Note the intensity of red staining on ACS coated with Osteogain ${ }^{\circledR}$ in comparison to control samples. b Quantified data of alizarin red staining from color thresholding software (double asterisks denote significantly higher than all other treatment modalities, $p<0.05$ )

to quantify the full range of proteins found in the enamel matrix. In the present study, it was found that amelogenins efficiently adsorbed onto collagen sponges and that a 0.3-mL volume of Osteogain® was sufficiently soaked up by ACS following a 5-min coating period. A PBS rinse was performed to determine if the proteins in EMD would be dissolved/dissociated from the surface after this initial 5-min coating period. It was however found that approximately $98 \%$ of original content remained within ACSs and approximately $70 \%$ of the total amelogenin content remained present within ACS even after a 10-day period, demonstrating excellent retention of the loaded proteins over time. These results were significantly better than previous reports performed by our group demonstrating the ability for Osteogain ${ }^{\circ}$ to adsorb to bone grafting materials including NBM, DFDBA, and a synthetic calcium phosphate material [22]. The results from the present study demonstrate almost a 2 -fold increase in adsorbed amelogenin to the surface of collagen sponges after
10 days when compared to synthetic bone grafts, confirming the preferred potential of collagen to serve as an ideal matrix for amelogenin adsorption.

Thereafter, the effect of combining Osteogain ${ }^{\circledR}$ to ACSs was investigated on ST2 cell adhesion, proliferation, and differentiation towards osteoblasts when compared to standard tissue culture plastic (Fig. 2, 3, and 4). It was first found that Osteogain ${ }^{\circledR}$ significantly induced a $50 \%$ increase in cell attachment to ACSs. Previously, Hoang et al. reported that amelogenin acts as a cell adhesion molecule capable of facilitating cell attachment [33]. The results from our study further confirm the ability for amelogenin to improve cell adhesion specifically when Osteogain $₫$ was coated to a biomaterial surface. Thereafter, it was found that Osteogain ${ }^{\circledR}$ decreased cell proliferation and increased cell differentiation. These findings are in agreement with previous reports demonstrating that as pre-osteoblasts undergo cell differentiation more rapidly, typically a decrease in cell proliferation is observed in parallel [34]. Interestingly, previous reports from our group have found that Osteogain $®$ (and EMD in general) is able to promote cell proliferation when compared to either control tissue culture plastic alone or to biomaterial alone [23, 35-37]. One potential reason for the observed differences in the present study may be due to the difficulty of cells to migrate and proliferate across a collagen fleece matrix when compared to bone grafting materials or standard tissue culture plastic; however, future investigation is necessary to further clarify this hypothesis.

The main important findings from the present study were the ability for Osteogain ${ }^{\circledR}$ to significantly upregulate cell differentiation of progenitor cells towards a more mature osteoblastic phenotype by 14 days (Figs. $3 \mathrm{~d}$ and 4 ). These findings are consistent with recent results from our group that have shown the differentiation potential of Osteogain $® / E M D$ on various cell lines and human primary cells [23, 35-37]. In the present study, we aimed to research a highly clinically applicable clinical scenario by combining Osteogain ${ }^{\circledR}$ with a more suitable biomaterial for clinical practice. Currently, Osteogain ${ }^{\circledR}$ is being investigated for its combination with ACS in two indications in both large animal studies (monkeys) and humans for its potential to speed regeneration of both extraction socket healing and intrabony/furcation periodontal defect regeneration. This preliminary in vitro data supports the fact that the combination of Osteogain with ACS mainly induces cell activity of osteoblast progenitor cells to differentiate towards mature osteoblasts by demonstrating higher mRNA levels of osteoblast differentiation markers as well as alizarin red staining.

Recent findings from our group have also demonstrated that Osteogain $₫$ is able to stimulate new bone formation in vivo in pure bone defects when combined with a bone grafting material in small rodent animals [24]. The sum of these previous in vitro and in vivo studies warrants more 
investigation of Osteogain ${ }^{\circledR}$ in large animal models. Future strategies aimed directly at studying the regenerative potential of Osteogain ${ }^{\circledR}$ in combination with an ACS in vivo are further needed to fully characterize the potential to minimize ridge alterations post extraction, utilizing the combination approach used in this study.

\section{Conclusion}

The findings from the present study demonstrate that ACSs are efficiently able to adsorb amelogenins, the main protein in Osteogain $®$, and release them to the surrounding environment over a 10-day period. Furthermore, the combination of Osteogain $®$ with ACS significantly upregulated cell adhesion by $50 \%$, increased mRNA levels of osteoblast differentiation markers between 2- and 6-fold, and further supported the mineralization of osteoblast in vitro. Further animal and human clinical trials are now necessary to evaluate the regenerative potential of Osteogain $®$ in combination with ACS in extraction sockets following tooth loss.

\section{Compliance with ethical standards}

Conflict of interest Osteogain ${ }^{\circledR}$ was kindly supplied by Straumann AG, Switzerland. ACS was provided by Botiss AG, Germany. The authors declare that they have no conflict of interests.

Funding This work was fully funded by the Cell Biology Laboratory at Nova Southeastern University, College of Dental Medicine.

Ethical approval No ethical approval was required for this study as human participants or animals were not utilized in this study.

Informed consent For this type of study, informed consent was not required as no human or animal subjects were utilized.

\section{Reference}

1. Johnson K (1963) A study of the dimensional changes occurring in the maxilla after tooth extraction.- part I. Normal healing. Aust Dent J 8:428-433

2. Araújo MG, Lindhe J (2005) Dimensional ridge alterations following tooth extraction. An experimental study in the dog. J Clin Periodontol 32:212-218

3. Chappuis V, Engel O, Reyes M, Shahim K, Nolte LP, Buser D (2013) Ridge alterations post-extraction in the esthetic zone: a 3D analysis with CBCT. J Dent Res 92:195s-201s. doi:10.1177 /0022034513506713

4. Brkovic BM, Prasad HS, Konandreas G, Milan R, Antunovic D, Sandor GK, Rohrer MD (2008) Simple preservation of a maxillary extraction socket using beta-tricalcium phosphate with type I collagen: preliminary clinical and histomorphometric observations. J (Canadian Dental Association) 74:523-528
5. Brkovic BM, Prasad HS, Rohrer MD, Konandreas G, Agrogiannis G, Antunovic D, Sandor GK (2012) Beta-tricalcium phosphate/ type I collagen cones with or without a barrier membrane in human extraction socket healing: clinical, histologic, histomorphometric, and immunohistochemical evaluation. Clin Oral Invest 16:581590. doi:10.1007/s00784-011-0531-1

6. Mardas N, Chadha V, Donos N (2010) Alveolar ridge preservation with guided bone regeneration and a synthetic bone substitute or a bovine-derived xenograft: a randomized, controlled clinical trial. Clin Oral Implants Res 21:688-698. doi:10.1111/j.16000501.2010.01918.x

7. Wallace S (2015) Histomorphometric and 3D cone-beam computerized tomographic evaluation of socket preservation in molar extraction sites using human particulate mineralized cancellous allograft bone with a porcine collagen xenograft barrier: a case series. J Oral Implantol 41:291-297. doi:10.1563/aaid-joi-D-14-00078

8. Bayat M, Momen Heravi F, Mahmoudi M, Bahrami N (2015) Bone reconstruction following application of bone matrix gelatin to alveolar defects: a randomized clinical trial. Int J Organ Transplant Med 6:176-181

9. Mardas N, D'Aiuto F, Mezzomo L, Arzoumanidi M, Donos N (2011) Radiographic alveolar bone changes following ridge preservation with two different biomaterials. Clin Oral Implants Res 22: 416-423. doi:10.1111/j.1600-0501.2010.02154.x

10. Coomes AM, Mealey BL, Huynh-Ba G, Barboza-Arguello C, Moore WS, Cochran DL (2014) Buccal bone formation after flapless extraction: a randomized, controlled clinical trial comparing recombinant human bone morphogenetic protein 2/absorbable collagen carrier and collagen sponge alone. J Periodontol 85:525535. doi:10.1902/jop.2013.130207

11. Fiorellini JP, Howell TH, Cochran D, Malmquist J, Lilly LC, Spagnoli D, Toljanic J, Jones A, Nevins M (2005) Randomized study evaluating recombinant human bone morphogenetic protein-2 for extraction socket augmentation. J Periodontol 76: 605-613. doi:10.1902/jop.2005.76.4.605

12. Misch CM (2010) The use of recombinant human bone morphogenetic protein-2 for the repair of extraction socket defects: a technical modification and case series report. Int J Oral Maxillofac Implants 25:1246-1252

13. Wallace SC, Pikos MA, Prasad H (2014) De novo bone regeneration in human extraction sites using recombinant human bone morphogenetic protein-2/ACS: a clinical, histomorphometric, densitometric, and 3-dimensional cone-beam computerized tomographic scan evaluation. Implant Dent 23:132-137. doi:10.1097 /id.0000000000000035

14. De Risi V, Clementini M, Vittorini G, Mannocci A, De Sanctis M (2015) Alveolar ridge preservation techniques: a systematic review and meta-analysis of histological and histomorphometrical data. Clin Oral Implants Res 26:50-68. doi:10.1111/clr.12288

15. Jambhekar S, Kernen F, Bidra AS (2015) Clinical and histologic outcomes of socket grafting after flapless tooth extraction: a systematic review of randomized controlled clinical trials. J Prosthet Dent 113:371-382. doi:10.1016/j.prosdent.2014.12.009

16. Moraschini V, Barboza ED (2016) Quality assessment of systematic reviews on alveolar socket preservation. Int J Oral Maxillofac Surg. doi:10.1016/j.ijom.2016.03.010

17. Spagnoli D, Choi C (2013) Extraction socket grafting and buccal wall regeneration with recombinant human bone morphogenetic protein-2 and acellular collagen sponge. Atlas Oral Maxillofac Surg Clin North Am 21:175-183. doi:10.1016/j.cxom.2013.05.003

18. Morjaria KR, Wilson R, Palmer RM (2014) Bone healing after tooth extraction with or without an intervention: a systematic review of randomized controlled trials. Clin Implant Dent Relat Res 16:1-20. doi:10.1111/j.1708-8208.2012.00450.x

19. Tan WL, Wong TL, Wong MC, Lang NP (2012) A systematic review of post-extractional alveolar hard and soft tissue 
dimensional changes in humans. Clin Oral Implants Res 23(Suppl 5):1-21. doi:10.1111/j.1600-0501.2011.02375.x

20. De Sarkar A, Singhvi N, Shetty JN, Ramakrishna T, Shetye O, Islam M, Keerthy H (2015) The local effect of alendronate with intra-alveolar collagen sponges on post extraction alveolar ridge resorption: a clinical trial. J Maxillofac Oral Surg 14:344-356. doi:10.1007/s12663-014-0633-9

21. Zhang Y, Yang S, Zhou W, Fu H, Qian L, Miron RJ (2015) Addition of a synthetically fabricated osteoinductive biphasic calcium phosphate bone graft to BMP2 improves new bone formation. Clin Implant Dent Relat Res. doi:10.1111/cid.12384

22. Miron RJ, Bosshardt DD, Buser D, Zhang Y, Tugulu S, Gemperli A, Dard M, Caluseru OM, Chandad F, Sculean A (2015) Comparison of the capacity of enamel matrix derivative gel and enamel matrix derivative in liquid formulation to adsorb to bone grafting materials. J Periodontol 86:578-587. doi:10.1902 /jop.2015.140538

23. Miron RJ, Chandad F, Buser D, Sculean A, Cochran DL, Zhang Y (2016) Effect of enamel matrix derivative liquid on osteoblast and periodontal ligament cell proliferation and differentiation. $\mathrm{J}$ Periodontol 87:91-99. doi:10.1902/jop.2015.150389

24. Zhang Y, Jing D, Buser D, Sculean A, Chandad F, Miron RJ (2016) Bone grafting material in combination with Osteogain for bone repair: a rat histomorphometric study. Clin Oral Invest 20:589595. doi:10.1007/s00784-015-1532-2

25. Miron RJ, Sculean A, Cochran DL, Froum S, Zucchelli G, Nemcovsky C, Donos N, Lyngstadaas SP, Deschner J, Dard M, Stavropoulos A, Zhang Y, Trombelli L, Kasaj A, Shirakata Y, Cortellini P, Tonetti M, Rasperini G, Jepsen S, Bosshardt DD (2016) 20 years of enamel matrix derivative: the past, the present and the future. J Clin Periodontol. doi:10.1111/jepe.12546

26. Boyan BD, Weesner TC, Lohmann CH, Andreacchio D, Carnes DL, Dean DD, Cochran DL, Schwartz Z (2000) Porcine fetal enamel matrix derivative enhances bone formation induced by demineralized freeze dried bone allograft in vivo. J Periodontol 71:1278-1286. doi:10.1902/jop.2000.71.8.1278

27. Kauvar AS, Thoma DS, Carnes DL, Cochran DL (2010) In vivo angiogenic activity of enamel matrix derivative. J Periodontol 81: 1196-1201. doi:10.1902/jop.2010.090441
28. Neeley WW, Carnes DL, Cochran DL (2010) Osteogenesis in an in vitro coculture of human periodontal ligament fibroblasts and human microvascular endothelial cells. J Periodontol 81:139-149. doi:10.1902/jop.2009.090027

29. Schlueter SR, Carnes DL, Cochran DL (2007) In vitro effects of enamel matrix derivative on microvascular cells. J Periodontol 78: 141-151. doi:10.1902/jop.2007.060111

30. Thoma DS, Villar CC, Carnes DL, Dard M, Chun YH, Cochran DL (2011) Angiogenic activity of an enamel matrix derivative (EMD) and EMD-derived proteins: an experimental study in mice. J Clin Periodontol 38:253-260. doi:10.1111/j.1600-051X.2010.01656.x

31. Miron RJ, Hedbom E, Saulacic N, Zhang Y, Sculean A, Bosshardt DD, Buser D (2011) Osteogenic potential of autogenous bone grafts harvested with four different surgical techniques. J Dent Res 90: 1428-1433. doi: $10.1177 / 0022034511422718$

32. Schmittgen TD, Livak KJ (2008) Analyzing real-time PCR data by the comparative CT method. Nat Protoc 3:1101-1108

33. Hoang AM, Klebe RJ, Steffensen B, Ryu OH, Simmer JP, Cochran DL (2002) Amelogenin is a cell adhesion protein. J Dent Res 81: 497-500

34. Quarles LD, Yohay DA, Lever LW, Caton R, Wenstrup RJ (1992) Distinct proliferative and differentiated stages of murine MC3T3E1 cells in culture: an in vitro model of osteoblast development. J Bone Miner Res 7:683-692. doi:10.1002/jbmr.5650070613

35. Miron RJ, Bosshardt DD, Hedbom E, Zhang Y, Haenni B, Buser D, Sculean A (2012) Adsorption of enamel matrix proteins to a bovine-derived bone grafting material and its regulation of cell adhesion, proliferation, and differentiation. J Periodontol 83:936947. doi:10.1902/jop.2011.110480

36. Miron RJ, Caluseru OM, Guillemette V, Zhang Y, Buser D, Chandad F, Sculean A (2015) Effect of bone graft density on in vitro cell behavior with enamel matrix derivative. Clin Oral Invest 19:1643-1651. doi:10.1007/s00784-014-1388-x

37. Miron RJ, Fujioka-Kobayashi M, Zhang Y, Caballe-Serrano J, Shirakata Y, Bosshardt DD, Buser D, Sculean A (2016) Osteogain improves osteoblast adhesion, proliferation and differentiation on a bovine-derived natural bone mineral. Clin Oral Implants Res. doi:10.1111/clr.12802 